\title{
Study on Relationship between Scientific and Technological Resource Sharing and Regional Economic Development
}

\author{
Ya Nie \\ Shijiazhuang University of Economics, Shijiazhuang, Hebei 050031, China
}

Keywords: Scientific and technological resource, Regional economy, Relationship research

\begin{abstract}
Economic development level improves continually. Science and technology also improve and develop continuously. The implementation of the strategy that science and technology rejuvenate a country facilitates technological innovation. Therefore, science and technology become the primary productive force concerning social development. But, on the whole, scientific and technological resource allocation and utilization rate are low in China. Technology transfer and sharing can not meet production status, and regional problem becomes severer. All these become the major problems restricting technological innovation and harmonious economic development. This paper will analyze these from such perspectives as scientific and technological resource sharing and allocation, technology transfer and harmonious development of regional economy and proposes the countermeasures for scientific and technological resource sharing and technology transfer.
\end{abstract}

\section{Introduction}

In the theories of scientific and technological resource allocation and harmonious development of regional economy, most researches involve macroscopic aspect, but microscopic theories are few. Besides, most researches only rest on a field. The researches on scientific and technological resource allocation, technology transfer and microcosmic mechanism are few. To specify the relationship between scientific and technological resource sharing and regional economic development, balance the two, make them complete each other and make contributions to regional economic development, the research and exploration of the two aspects should be enhanced.

\section{Theories of scientific and technological resource allocation, technology transfer and regional economic development}

\section{Basic overview of system}

"System" was proposed by a foreign biologist, which means the system exists in correlated environment. Besides, it also expresses the sum of various relations and various parts in the environment. The system is an organic whole which is composed of several correlated elements. The system has many features, such as strong element nature and correlation. The element is the unit of forming a system and also the foundation and carrier for the existence of system. As well, it is an important foundation of constituting system hierarchy and duality. Different hierarchy of elements forms a system and constitutes the unit. These hierarchies are correlated. Most elements are sub-systems, except their subordinate position. Correlation refers to the relation link of elements in the system. In other words, the change and existence of one element are related to other elements. The system is a whole, rather than a function. Each whole needs to be achieved by interactions of elements. Different elements in the system are related to the whole function. The correlated contents include material flow, energy flow and information flow. Material flow and energy flow are the foundation of information flow. Thus, various elements keep the relationship of system and environment. In essence, all systems own correlation feature. In addition, structure property is also the major feature. Structure refers to organic integration and correlation of different elements in the system in the space or region. The elements can be arranged and interacted in a good order. Material system structure is divided into space structure and time structure. Space structure decides system stability, while time structure has variability. Space structure and time structure in each system should be uniform ${ }^{[1]}$. 


\section{Principles of system}

Integrality. The fundamental of system is integrality. Different elements are correlated and interacted to form orderly and integrated results. Thus, integrality principle of system is different from the function of components. Correlation principle. Organic property of system is the core of system theory and the existence relationship between different elements and system and in the environment. This theory shows that the correlation of internal elements of integral system exists organically. Only when various elements interact and correlate can system integrality form. The principle of order. Various elements in the system are arranged orderly in spatial combination. All systems are orderly.

\section{Definition of system elements and environment and the operating mechanism}

\section{Scientific and technological resource allocation, definition of sharing concept and connotation}

Science and technology are a kind of experience and skills generated in human production, nature and society transformation. The fundamental approach of human knowledge and wealth increase is technological innovation and development. In turn, social progress and development can promote technological innovation and invention and accumulate human wealth. Resources are divided into social resource and natural resource. The concept is defined as follows: resources are natural factors and conditions which are created by human in certain period, place and condition and benefit human. Scientific and technological resource is a category of resources and refers to the sum of resource factors inputted by scientific and technological activities ${ }^{[2]}$.

\section{Definition of concept and connotation of regional economy system}

Regional economy means humans produce, operate and allocate resources in the fixed region so that these contents become a whole which can be interacted and influenced mutually. Regional economy follows certain rules, i.e. add spatial element, economic status and operation rules. Regional economy can generate certain spatial and geographical effect under economic mechanism. Regional economy herein is generated under specific conditions, material production and regular operation state. In regional economy, humans play the leading role. Hence, human subjective will decides the quality of production link. Humans have the right to utilize natural resources and capital in regional economy system. Regional economy system owns multiple regional economy system and present nonlinear complexity. Different elements in the system are crossed and interacted. Hence, the system owns complex and nonlinear coupling function. Meanwhile, regional economy can operate in external environment and keeps lasting and dynamic nonlinear collaborative mechanism.

\section{Evaluation of microcosmic allocation efficiency of regional scientific and technological resource}

\section{Microcosmic allocation mechanism of regional scientific and technological resource}

Allocation mechanism of government's scientific and technological resource

Government is the leader of regional scientific and technological resource allocation. Financial resource allocation can macroscopically regulate and supervise the market. Under the general market environment, private persons cannot invest in public welfare projects, such as traffic, health and environmental protection. Moreover, they have no right to invest in the projects with high return on investment, high risk and large scale. Within the scope of scientific and technological investment, the market will be out of control. At this time, the government needs to exert its function and to make up for shortcomings of private investment.

Management mechanism of government's scientific and technological resource input

Fiscal expenditure of government sector includes science and technology expenditure and belongs to public financial management field. Its objective is to meet social public demand and offer superior and convenient service and product for society. Hence, its basic feature is public property. 
Furthermore, realization mechanism or procedure is the key of reflecting public financial fairness. Democratized and legalized public choice mechanism needs to be established to achieve financial public property, own more transparent, integral and open budget management system and create conditions for scientific and technological resource sharing and harmonious development of regional economy ${ }^{[3]}$.

Orientation of government's scientific and technological input management function

Scientific and technological input is conducted in combination of basic features and operation basis of public finance. The boundary of government and market should be divided to specify the government's responsibility, and solve such problems as market resource allocation, public welfare study and trial development activity input etc. Secondly, it is required to mainly resolve key science and technology project input problems which are not solved according to market mechanism.

Government's scientific and technological input management mode

Under the guidance of market economy, it is necessary to give full play to macro-control function of market. Government's scientific and technological input can complete the preset objective only when the relation between government and market is correctly positioned, and diversified management mode is established. The management mode based on policy guidance guarantees rational and optimized system arrangement.

\section{Microcosmic allocation mechanism of human resource of regional science and technology}

Scientific and technological human resource has numerous features, such as renewability and periodicity with social property. Besides, it also has the following features: high cost: a lot of resources and funds are needed to cultivate an excellent scientific and technological talent, including the energy of receiving education and training, cost, economic cost of family and personal income as well as the public cost of educational infrastructure etc ${ }^{[4]}$. Thus, one of essential features of human resource is high cost. High intelligence: the talents engaging in technical research, development and innovation should not just own basic technological accomplishment and culture knowledge, but also have keen intuition of science and technology and continuous technological creation and research impetus. Therefore, the intelligence level of talents receiving high education and training in human resource is generally higher than that of common people. High creativity: high intelligence is correlated to high creativity, which is also a basic feature of human resource. Scientific and technological activity itself owns exploration property and practice property. The work on research, development and creation is actually the process of creation. Scientific and technical personnel or researchers are required to own the foundation and conditions of innovation activity.

\section{Material resource allocation mechanism of regional scientific and technological foundation}

Material resource of regional science and technology involves such contents as financial resource of regional science and technology, and financial input of regional science and technology. In economic development of regional science and technology, the role of material resource allocation is exerted in the form of inventory. Research and development institutions, colleges, technology research and development organizations, intentional laboratories and regional key laboratories in the region need material resource. Material resource sharing management mode of regional scientific and technological foundation needs to follow basic rules of scientific and technological operation on the basis of scientific and technological economic policy and to adopt the coordinated management mode which combines centralized management and decentralized management.

To enhance regional overall planning

The government sector should formulate med-term and long-term material resource input sharing mechanism and plan material resource input sharing in accordance with laws, regulations, material resource allocation of regional science and technology as well as regional economic development. It is required to coordinate material resource of multiple scientific and technological foundations to make material resource of regional scientific and technological foundation shared and enhance resource intensification level. 
To deepen technological management and system innovation

After regional overall planning is completed, work efficiency of relevant functional departments will decide macro-management system construction efficiency of material resource sharing of scientific and technological foundation. Hence, the government and other service departments need to reform and innovate for function orientation, and administrative execution system of administrative execution management, specify the right and responsibility of different departments and industries in the region, make charging standards and rules open and improve the efficiency of regional scientific and technological management execution system.

\section{Construction of scientific and technological resource sharing platform and support of regional economic development}

\section{To set up urban technological innovative ability information service platform}

Urban technological innovative ability information service platform contains technological innovative ability information service portal and technological innovative ability information service which are mainly applied in urban technological innovation and information service application supporting platform. Urban technological innovative ability contains many information resources and offers rich information service functions. It is a user-oriented one-stop service platform. JS158Portlet standard based on national standard and XML information processing technology apply Web Service calculation mode. They can support achievement of uniform information service portal framework system. Technological innovative ability information service platform based on SP application mode takes advantage of information service period to deploy, monitor and maintain supporting environment. The application software based on XML information processing and Web service technology offers application information, integrates the environment in Web service link and shows user interface to users in the form of uniform leasing. Urban technological innovative ability information supporting platform of a city is based on public service system, can bear multiple information services and incorporate them in uniform system supporting platform. Such system platform plays a pivotal role in application service and bear information exchange function and operation support in the whole service. Application supporting platform is composed of XML data resource integration, UDDI resource service retrieval, Web service application integration and SOA application mode etc.

\section{To establish leadership decision supporting platform}

Leadership decision supporting platform is an important system in the internal network of the government, which is integrated by multiple information systems. Uniform network office platform is established. This system mainly solves the following problems: data sources disperse; information of each department cannot be transmitted between the superior and the subordinate; information preservation management is complex. The system can offer scientific and rational decision for people. This system applies information technology, database technology and advanced decision-making means, provides basis for comprehensive service through system data processing and analysis, makes the decision more democratic and open and regional economy development is more harmonious. This system includes data collection, statement formulation, multi-dimensional statistics, prediction analysis and background data query etc. Thus, data can gain uniform scientific management, and index data are analyzed and predicted from different aspects. The system can integrate key subjects, such as mathematical statistics, econometrics, database and computer science. Under the help of the system, macroeconomic information resource can be integrated and optimized. More scientific method may be used to sort, arrange and combine the economic data and to fully dig the hidden information. In this way, users can see the interface more clearly, and transform the dull data to the graphs. Besides, monitoring, analysis sand prediction of operation state of regional economy will be clearer and more vivid ${ }^{[5]}$. 
To set up technological innovation information service platform of science and technology industry park

It is necessary to drive scientific and technological information resource sharing and allocation by the level of productive forces and set up technological innovation information service platform of science and technology industry park. Main methods include: web portals, scientific and technical literatures, science and technology projects, scientific and technological achievements, talent information, park coordination, enterprise website, product display and network collaborative design etc. The main purpose is to offer more scientific decision for the enterprises in the park, to provide support of investment attraction, statistic analysis and product innovation for the park and to drive development and integration of regional economy.

\section{Conclusion}

This paper mainly explores the relationship between scientific and technological resource sharing and regional economy development, introduces the connotation and features of scientific and technological resource allocation and sharing and proposes several countermeasures to drive regional economic construction and development in order to facilitate mutual harmonious development of scientific and technological resources and regional economy development.

\section{Acknowledgement}

This paper belongs to the research topic of Hubei Science and Technology Department in 2015; topic title: Study on Scientific and Technological Collaborative Innovation Mode and Countermeasures in Beijing-Tianjin-Hebei Region; No.: 154576288

\section{References}

[1] Gao Li, Shao Yingying, Chen Fangzheng et al., On Regional Innovation Capability and Technological Talent Resource Sharing- Case Study of "Wuhan Urban Circle". China Education Innovation Herald, 2010(15):174-175.

[2] Yang Yuhan, Construction of characteristic scientific and technological resource Network Service System and Service for Regional Economy Construction-Case Study of Coal and Electrochemical Scientific and Technological Resources in East Heilongjiang Province. Economist, 2012(8):204-206.

[3] Yu Zhongjun, Kong Lingjuan, Liang Dongrong et al., Study on Talent Resource Sharing Mechanism in Regional Economic Development - Case Study of Jinan Urban Circle. China Business \& Trade, 2013(16):165-166.

[4] Zhan Zhaolei, Prominent Problems and Promotion Mechanism of Independent Innovation Demonstration Area Construction in South Jiangsu. Science \& Technology Progress and Policy, 2013,30(5):37-41.

[5] Zheng Sujuan, Huang Dongmin, Joint Construction of Practical Teaching Base Resource Sharing Strategy by Colleges in Beijing-Tianjin-Hebei Region-from Perspective of Practical Teaching Base of Ideological and Political Theory Course. Journal of Langfang Teachers College (Social Science Edition), 2013,29(3):104-106. 